\title{
Percutaneous Transvenous Mitral Commissurotomy: SGNHC Experience
}

\author{
Dr Rajib Rajbhandari, Dr Man Bdr KC, Dr Y Bhatt, Dr Shyam Regmi, Dr \\ Deewakar Sharma, Dr Sujeeb Rajbhandari, Dr Subodh Kansakar, Dr \\ Rabi Malla, Dr Y R Limbu, Dr Bhagawan Koirala, Dr N K Shrestha
}

One hundred patients had PTMC from June 2003 to January 2004, Seventy four percent of them were female. Youngest was 10 years and oldest was 58 years, Mean age was 25 years. Under 21 years were $26 \%$, Atrial fibrillation was present in $32 \%$,

Mean MVA increased from range $0.91 \mathrm{~cm} 2$ to $1.90 \mathrm{~cm} 2$ with range of $0.5 \mathrm{~cm}$ ? preprocedure to $2.3 \mathrm{~cm} 2$ post-procedure, Left atrial mean pressure decreased from average $19 \mathrm{~mm} \mathrm{Hg}$ to $6 \mathrm{~mm} \mathrm{Hg}$. Subjective improvement was reported in 99\%. There was no mortality. Significant MR (>2 Grade) was noted in 3 patients (3\%) post- procedure. None developed severe MR. Procedure failed in two patients. None had cardiac tamponade. None had to undergo emergency surgery. One had systemic embolisation during the procedure which recovered subsequently. 